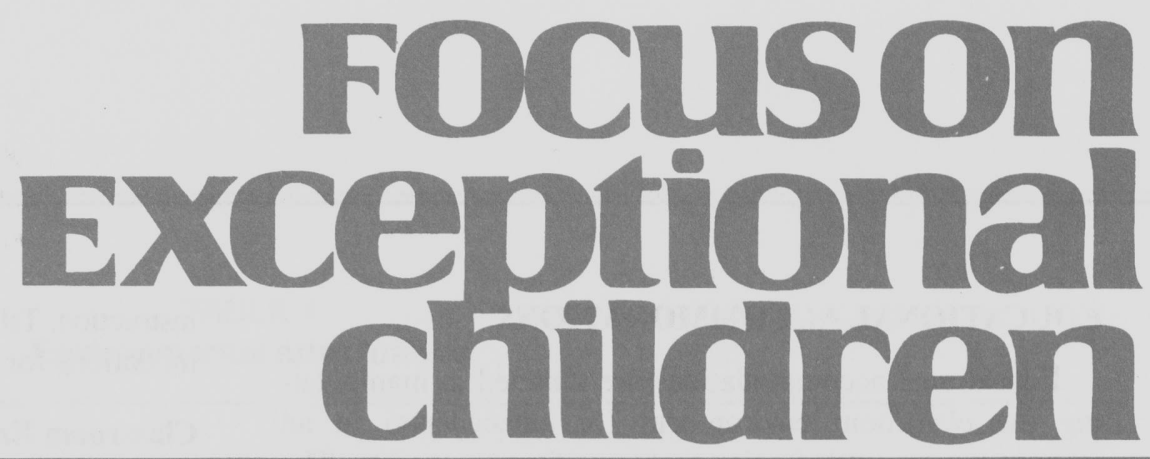

\title{
Attention Deficit Hyperactivity Disorder: Effective Methods for the Classroom
}

\author{
Robert Reid
}

Attention deficit hyperactivity disorder (ADHD) is estimated to affect from 3 to 5 percent of school-age children (APA, 1994). ADHD currently is conceptualized as a neuropsychological disorder that has a strong genetic component but that also is affected by environmental factors (Barkley, 1998). Although a number of promising lines of research are emerging, at present the cause(s) of ADHD remains uncertain (Barkley, 1998). Children who exhibit the behaviors characteristic of ADHD often have difficulty attending to tasks, remaining seated, and resisting distractions, and they often act impulsively (APA, 1994). In addition, children with ADHD may be noncompliant or aggressive, or may exhibit other disruptive behaviors.

Children with ADHD also are more likely than their peers to have academic problems. Research suggests that, in school-based samples, around $50 \%$ of children with ADHD will qualify for special education, the majority of whom qualify under either the Learning Disability or Behavioral Disorders category (Reid, Maag, Vasa, \& Wright, 1994), and most children with ADHD also should qualify for service under Section 504 (Reid \& Katsiyannis, 1995). ADHD, however, is not strictly a special education problem. Most children with ADHD will spend most of their time in the general education classroom (Reid, Maag, Vasa, \& Wright, 1994). Thus, effectively working with children with ADHD demands attention to both the general education and special education environments.

At present, a multimodal approach to ADHD treatment is the most widely accepted approach (e.g., Barkley, 1998; DuPaul \& Stoner, 1994). The model includes four major areas in which intervention may be addressed: (a) educational accommodations, (b) promoting appropriate behavior, (c) medical management, and (d) ancillary support services for children and parents (e.g. counseling, parental support groups). This article will focus on two facets of ADHD treatment: educational accommodations and interventions for promoting appropriate behavior. These areas are the ones in which the teacher, whether special education or general education, will be directly involved. The purpose of this article is to present a compendium of best practices recommended by research and practical experience.

Robert Reid is affiliated with the Department of Special Education and Communication Disorders, University of Nebraska at Lincoln. 


\section{EDUCATIONAL ACCOMMODATIONS}

Educational accommodations are directed at manipulating the classroom environment (or antecedents) in an attempt to prevent behavior problems from occurring. The goal is to alter the classroom environment to better fit the child's needs. Focusing on antecedents offers the advantage of being proactive rather than reactive. Changing antecedents often results in a swift and sizable positive change in behavior. Thus, manipulation of antecedents potentially offers a great deal of return on the teacher's investment of time and effort (Dunlap \& Kern, 1993).

Moreover, most classroom accommodations for manipulating antecedents are of the common-sense variety-simple to implement, practical, and most important, requiring minimal time and effort on the instructor's part.

This is an important consideration especially for the general education classroom. Teachers have limited time. In a class of 25-30 students, teachers cannot realistically devote most of their time to a single student. Most classroom accommodations can be grouped into three major areas: (a) classroom environment, (b) tasks/materials, and (c) curriculum/

\section{FOcuson Exceptional children}

ISSN 0015-511X FOCUS ON EXCEPTIONAL CHILDREN (USPS 203-360) is published monthly except June, July, and August as a service to teachers, special educators, curriculum specialists, administrators, and those concerned with the special education of exceptional children. This publication is annotated and indexed by the ERIC Clearinghouse on Handicapped and Gifted children for publication in the monthly Current Index to Journals in Education (CIJE) and the quarterly index, Exceptional Children Education Resources (ECER). The full text of Focus on Exceptional Children is also available in the electronic versions of the Education Index. It is also available in microfilm from Xerox University Microfilms, Ann Arbor, MI. Subscription rates: Individual, \$30 per year; institutions, \$40 per year. Copyright (C) 1999, Love Publishing Company. All rights reserved. Reproduction in whole or part without written permission is prohibited. Printed in the United States of America. Periodicals postage is paid at Denver, Colorado. POSTMASTER: Send address changes to:

$$
\begin{gathered}
\text { Love Publishing Company } \\
\text { Executive and Editorial Office } \\
\text { P.O. Box } 22353 \\
\text { Denver, Colorado } 80222 \\
\text { Telephone (303) 221-7333 }
\end{gathered}
$$

Edward L. Meyen University of Kansas

\section{Glenn A. Vergason} Georgia State University

Richard J. Whelan University of Kansas Medical Center
Thomas S. Love

Associate Editor instruction. Table 1 shows some common educational accommodations for students with ADHD.

\section{Classroom Environment}

This type of accommodation refers to classroom-management practices and the physical setup of the classroom. Changes in either classroom management or physical setup can have dramatic effects on students' behavior. There also is a potential synergy. For example, changing the environment may make management easier or more effective.

\section{Classroom management}

If teachers are to work successfully with children who have ADHD in any instructional environment (either special education or general education), good class management technique is essential. The goal here is to systematically instill appropriate behaviors and increase their frequency. The ability to behave appropriately within classroom constraints is a necessary prerequisite for the academic success of any child. Children with ADHD are hindered if the classroom is noisy, disorderly, or lacking clear consistent regimens and expectations. For children with ADHD to succeed, teachers need to (a) create and maintain a stable, predictable, structured instructional regimen, and (b) effectively communicate expectations.

Creating a stable instructional regimen is simple and straightforward. It involves making a written schedule of daily activities in which the school day is divided into blocks of time; posting it prominently (typically on a designated spot on the chalkboard); and maintaining this daily routine (Bender \& Mathes, 1995; DuPaul \& Stoner, 1994). Within each block of time, the daily schedule should state clearly the activities and the tasks for students to perform. Teachers should provide reminders and cues about what is needed to start and complete the activities (e.g., "You need to have your reading workbook and a pencil"). Teachers should schedule core academics and content that might be most cognitively challenging during the morning hours, and hands-on or less demanding activities in the afternoon, because research indicates that the behavior of children with ADHD often deteriorates over the course of the day (Pfiffner $\&$ Barkley, 1998). For this reason, the instructional schedule should fit the periods when the child is able to perform at his or her peak whenever possible.

A final consideration in scheduling pertains to preferred versus nonpreferred activities. Best practice suggests that teachers schedule nonpreferred activities before preferred activities and make preferred activities contingent upon successful completion of nonpreferred activities. For example, math seatwork would be scheduled (and must be completed) before the student could participate in a 15 -minute free-reading period. 
TABLE 1

Environmental adaptations

\section{Problem Accomodations}

Easily distracted, minor discipline problems

Problems getting started with work and following classroom routines

Staying in seat, fidgety

Sloppiness, disorganization, fails to complete or return assignments

\section{Difficulty completing work or maintaining effort}

The "bad day"
Seat the student where it is easy to monitor behavior; provide frequent feedback on behavior Seat the student near children who will provide positive models and who can ignore inappropriate behaviors

Provide study carrels to serve as special work areas

Arrange seating to minimize distractions (e.g., row vs tables)

Remove "temptations" (e.g., don't seat child next to the gerbil cage)

Create a daily schedule and maintain it. Teach the daily routine to students and reinforce compliance. Establish class rules, teach rules, post rules prominently, provide the student with additional cues, reinforce the student for following rules

Reinforce the student for starting tasks on time

Cue the student about future events or tasks that will require extra control

Establish/teach a transition routine and procedures; reinforce appropriate transitions

Cue the student when a transition is about to occur

Let the student serve as class runner, help clean classroom, do errands, straighten desks, sharpen pencils, etc.

Provide a stand-up desk

Allow the student to stand during group lessons or small-group activities

Provide several desks and allow the student to move between them

Provide substitute motor or verbal response to make while waiting (allow the student to chew gum or manipulate safe objects such as Nerf balls)

Use activity reinforcers

Write out assignments on the board or in an assignment notebook

Organize the student's locker or desk; create specific areas for books, notebooks, etc.

Use folders with places for completed work, work to be turned in, new assignments

Tape prompts to desk/locker ("Remember to bring ...")

Use assignment notebooks, time charts, and organizational aids; supervise and reinforce their use Practice planning by teaching how to break an activity into parts; teach necessary skills directly (e.g., outlining skills, sorting, ordering)

Keep homework to a minimum, and make sure assignments are at the appropriate difficulty level

Break instructional sessions into short time periods

Break assignments into short chunks; intersperse different content areas (e.g., 15 math problems, 5 spelling practice words, 3-minute oral reading)

Avoid unnecessary homework

Reduce the length of written assignments as much as possible

Use a word processor if possible to minimize recopying and help with spelling problems

If a student simply can't stay seated, arrange for him/her to signal you, then go outside to the hallway to let off energy (e.g., run-in-place for 60 seconds)

If the student is about to "blow," have a prearranged cool-off location where the student can go until ready to return to class 
Communicating expectations requires teachers to establish appropriate, effective class rules and procedures, and to actively monitor behavior. Table 2 gives guidelines for creating effective class rules recommended by Paine and his colleagues (Paine, Radicchi, Rosellini, Deutchman, \& Darch, 1983). Students with ADHD might need additional prompts or cues to remind them of what is expected. One useful technique is to tape to the student's desk a prompt card listing important behaviors (e.g., "Am I doing my work? Am I listening to the teacher?"). Prompts serve to remind the student what he or she should be doing and to redirect behavior.

Monitoring student behavior is critical to effective management. Research is clear that children with ADHD require (and perform best) when they are given frequent feedback on their performance (DuPaul \& Stoner, 1994). Therefore, teachers must monitor frequently, and equally important, provide feedback to the student on his or her behavior. Two effective means for teachers to cue themselves to monitor a student and provide feedback are (Pfiffner and Barkley, 1998):

1. Place a number of coins in one pocket and transfer a coin each time the teacher monitors the student and provides feedback.
2. Use a timer or taped tones that occur at random intervals every few minutes. When the timer goes off (or when a taped tone occurs), the teacher is cued to monitor behavior and provide feedback. This method can also serve as a precursor to self-monitoring interventions (discussed below).

How teachers provide feedback is important. Research has shown that for children with ADHD, effective class rules result in improved behavior when they are combined initially with teacher praise/positive reinforcement for compliance with rules, and ignoring and mild reprimands (or punishers) for rule violations (Acker \& O'Leary, 1987; Pfiiffner \& O'Leary, 1987; Pfiffner, Rosen, \& O’Leary, 1985). Praise alone is not likely to be effective. Abramowitz and O'Leary (1991) provide the following tips for effective reprimands:

- Deliver reprimands in a calm, unemotional manner (preferably privately, not publicly).

- State reprimands firmly (e.g., "Start your work now").

- Make reprimands brief and to the point; otherwise, attention actually may serve to reinforce the inappropriate behavior or draw attention from other students.

- Give reprimands as soon as possible after the inappropriate behavior occurs.

TABLE 2

\section{Guidelines for effective class rules}

\section{Basic Guideline Description}

Have a few good rules

Keep rules short and simple

Keep rules positive

Post rules prominently

Teach the rules

Reinforce compliance
Most classrooms, should have three to five rules that cover a broad range of behaviors. If students cannot remember the rule, they are unlikely to follow it.

Rules should be brief and stated simply. If students cannot understand rules, they cannot follow them. This also makes it easier for the teacher to praise students for following the rule or correcting violations.

Rules should stress what the students should do rather than what they should not do (e.g., "Keep hands and feet to myself" instead of "No hitting").

Rules should be displayed where students are likely to see them (and thus be reminded). Refer to the posted rules when pointing out infractions.

Class behavior should be treated as another important facet of curriculum. Teach the rules. Discuss the meaning of rules and why they are necessary. Ask students to point out and model behavior that exemplifies following (and not following) rules.

Teachers should systematically monitor compliance and praise (or otherwise reinforce) students for following the rules. In addition, rule violations should result in mild punishment or reprimands. 
- Avoid giving mixed messages (some praise and some reprimand) or positive statements as this might reinforce the inappropriate behavior.

- Increase the effectiveness of reprimands through close proximity, eye contact, and physical contact (e.g., a firm hand on the shoulder).

After the child's behavior has improved and stabilized, reprimands (or punishment) can be gradually faded. This also could occur naturally. When behavior improves, reprimands may not be necessary any longer.

Along with good classroom rules, teachers must be able to convey directions clearly and effectively. Children must understand what they are expected to do if they are to successfully accomplish it. Some tips for giving effective directions include the following:

- Get attention before giving directions. Use physical proximity, touch, and eye contact to ensure attention.

- Keep directions short and to the point. Long, involved directions are difficult to remember and will cause students with ADHD to lose focus.

- Be specific in the behavior the student must perform (e.g., "Put your books in your desk and your workbook in your cubby" rather than, "Clean up your desks.")

- Avoid giving multi-step directions all at once. Instead give one or two steps (e.g., Get out your math book and turn to page 45), wait for compliance (and reinforce it), then continue with the next step.

- Keep directions clear. Use simple, appropriate language, provide examples, or model the task when possible.

- Give directions three times. First, give directions. Second, paraphrase directions. Third, provide an additional cue or reminder by writing the directions on the chalkboard or overhead.

- Check for understanding. Ask the student to repeat the directions or demonstrate understanding through performance.

Transitions often pose problems for students with ADHD. (Transition means moving from one class, group, activity, or subject to another.) These can be a major source of off-task or disruptive behaviors. By managing transitions efficiently, instruction will be more effective. Mastropieri and Scruggs (1994) presented several techniques for ensuring quick transitions.

1. Set aside certain times when transitions, such as getting a drink or sharpening a pencil, are to occur. Specifying certain times reduces the likelihood of off-task behaviors occurring during the instructional lesson.

2. Establish an expectation that students move from one activity to another quickly, and reinforce them for complying. For example, set a timer and let students know that if they have their reading books out by the time the bell sounds, they will earn 10 minutes of free time at the end of the class.

3. Tell students that any time they lose in transition they will have to make up during free time. Students quickly realize that off-task behavior will not be reinforced by avoiding completing their assignment.

\section{Physical Setup}

Physical setup refers to two factors: the actual classroom layout, and the students' location within the classroom. Children with ADHD are easily distracted by extraneous stimuli. The physical layout of the classroom is an important factor in reducing or eliminating potential distractions. Pfiffner and Barkley (1998) suggest that physically enclosed classrooms (classrooms with four walls) are more appropriate than open classrooms for children with ADHD. Open classrooms can pose problems for children with ADHD because they provide many more opportunities for distraction (e.g., the child might be distracted by another class's activities or by children coming and going) and might be noisier. For children with ADHD, these types of distractions can result in less time on-task and other problem behaviors (Whalen, Henker, Collins, Finck, \& Dotemoto, 1979). Creating a minimally stimulating environment, however, is not necessary (or desirable) (Abramowitz \& O’Leary, 1991). Class size also is important. An overcrowded classroom results in more distractions for the student, and less individual time from the teacher.

Physical changes also can help students who need physical activity. One straightforward accommodation is to provide desks: two desks in the front of the room, one on each side. Whenever a students needs physical activity, he or she simply moves to the other desk. Along with this, students are taught how to move from one desk to another (e.g., take all work/materials necessary, move directly to the new desk, don't speak to other students while making the move).

Another simple accommodation for students who need more physical activity is a stand-up desk-a desk that has been raised to approximately chest height, allowing the student to stand and work. This can be done quite simply by extending desk legs to the maximum or by placing the desk on blocks. Stand-up desks help allow for physical movement during independent work. Combining various types of seating arrangements may be desirable. For example, a child might have one normal desk, one stand-up desk, and one study carrel, each of which would be appropriate for different instructional activities.

The student's physical location in the classroom is important, too. General recommendations include seating the child in close proximity to the teacher (to allow for proximity 
control and encourage frequent monitoring and feedback) and away from high-traffic areas and potential visual or auditory distractions such as the doorway, window, or pencil sharpener (Bender \& Mathes, 1995).

For children with attention problems who have difficulty remaining on-task, one effective accommodation is to have them work in study carrels. These are a simple, inexpensive means of greatly decreasing distractions. One potential problem with study carrels is that some students may perceive them as punative, especially if they are used in conjunction with time-out. To avoid this problem, one clever teacher told her students that they could use carrels as a "special office." Using the "office" was contingent upon appropriate behavior ("the office is only for working"). Students were allowed to put up a sign with their name when they used their "office," and to sign up to reserve "office time," and they were encouraged to move to their special office whenever they felt distracted.

Seating arrangements and instructional grouping also can affect students with ADHD because of proximity to other students who might pose potential distractions or unwittingly reinforce inappropriate behavior. A number of studies have noted that peer attention can directly affect the behavior of children with ADHD (e.g., Lewis \& Sugai, 1996; Northrup et al., 1995; Umbreit, 1995). Students with ADHD should have individual desks (Pfiffner \& Barkley, 1998). Arranging desks in rows (rather than clusters of desks) during independent and large group work, and surrounding the child with students who are good behavioral models (students who maintain effort and who will ignore inappropriate behaviors) can help decrease potential distractions and thereby minimize inappropriate behavior (Bender \& Mathes, 1995; Pfiffner \& Barkley, 1998).

Small-group activities also can present problems for children with ADHD. These children sometimes perceive smallgroup activities as opportunities for social interaction or attention. The composition of groups might contribute to this problem. One straightforward solution is to place the child with ADHD in a group that does not include his or her friends (Umbreit, 1995).

\section{Task and Materials}

The second category of antecedents involves the effects of task and materials on student behavior. Keeping students with ADHD on-task during independent seatwork activities is often difficult because of less teacher supervision, fewer opportunities for interaction, and independent work requires students to self-regulate, which poses problems for children with ADHD.

Maintaining attention during group activities also can be difficult. Children with ADHD are more likely to display behavior problems when they are not actively responding or receiving frequent feedback on performance. Task and material factors that influence behavior of children with ADHD include task difficulty, task length, and the amount and type of feedback provided during task performance. Several strategies can be used to manipulate these factors.

\section{Task Difficulty}

The cognitive demands a task imposes are related directly to student behavior. Two important factors are related to task difficulty. First, matching the level of difficulty to the student's current level of performance is essential. If students do not have the prerequisite skills for doing the work or if the difficulty level is too high (i.e., the student cannot do the work with a high level of accuracy), students will become frustrated-a sure-fire recipe for behavior problems.

Students should have attained a high level of accuracy during guided practice before moving on to independent practice activities such as completing worksheets (Mastropieri \&Scruggs, 1994). This is even more important in the case of children with ADHD. Even a slight mismatch between task difficulty and student performance can affect behavior significantly. In a study comparing student behavior at two difficulty levels - one at which students were $75 \%$ accurate, and the other at which students were $90 \%$ accurate, students exhibited higher rates of disruptive behavior at the $75 \%$ level than the $90 \%$ level (DePaepe, Shores, Beck, \& Denny, 1996). Before assigning independent seatwork, the teacher should assess the student's performance to ensure that independent work is at the appropriate level of difficulty. One guideline is that the student should be $90 \%$ accurate before being given independent work.

Another problem lies in situations involving multi-step tasks (e.g., doing a book report), in which a student might have the preskills necessary to complete a task successfully but lacks an effective strategy (e.g., the student has no idea of how to organize effort). Giving students a job card providing step-by-step instructions on how to accomplish a task can help in this situation (Cohen \& de Bettencourt, 1988).

A second common problem is when students get "stuck." Students with ADHD may not know how to obtain help appropriately during seatwork activities if the teacher is unable to provide immediate assistance. One useful method for helping students learn to obtain assistance in an acceptable manner is the use of assistance cards (Paine et al., 1983). Teachers write "Please help me" on one side of the card and "Please keep working" on the other side, then fold it into a triangle and tape it to the student's desk.

When the student needs help, he or she flips the card to the side that says, "Please help me," cueing the teacher to provide assistance. If the teacher is busy with another student, he or she walks over and flips up the other side of the 
card (Please keep working), indicating that the student should go to the next problem. In this way, the child's request is acknowledged and he or she knows that the teacher will be back to help shortly.

The "study buddy" technique, in which students are paired with a peer who provides assistance when needed, also can be effective. Teachers should praise compliance (i.e., use of the card or study buddy) and administer mild reprimands for inappropriate help-seeking behavior (e.g., calling out).

\section{Task Length}

The length of tasks (amount of work assigned) also can affect behavior. Students with ADHD are much more likely to misbehave when too much work is required, especially during independent seatwork. Students with ADHD easily can feel overwhelmed and simply not start, or they might be unable to maintain attention and thus fail to complete the task. This is not surprising, as one of the defining characteristics of students with ADHD is a problem with maintaining attention, especially if the task is long, difficult, or repetitious.

The solution to this problem is straightforward: Shorten assignments, intersperse different activities within assignments, and provide frequent breaks or alternative activities. For example, rather than asking a student to complete an entire worksheet on one topic, give the student with ADHD 5 or 10 math problems to complete at a time. When those are completed, the student might be asked to practice five spelling words, then do oral reading. With this technique the student should be given one section at a time rather than an entire packet (Abramowitz, Reid, \& O'Toole, 1994). It is important to ensure that breaks, or other activities, are highly structured, and that breaks are awarded after the work has been completed.

One particularly troublesome area is written assignments. Many children with ADHD have poor handwriting, and written assignments are particularly laborious. Even more troublesome is rewriting or recopying. Reducing the length of written assignments and minimizing recopying (use of the word processor can be helpful here) offer solutions.

Homework, too, can pose a problem. School is a stressful environment for children with ADHD. Too much homework results in a situation where the student lacks time to "decompress" from classroom demands. Also, parents often must supervise the student to ensure completion, which is an additional source of stress for parent and child alike. As a result, the student might return to school upset, fail to complete work during class, and be assigned even more homework. A vicious cycle then ensues in which the student's behavior deteriorates rapidly. Therefore, homework should be kept to the absolute minimum, and the teacher should not assign uncompleted class work as homework.

\section{Feedback}

Students with ADHD typically perform better when they receive frequent feedback on their performance (Barkley, 1998). Self-correcting materials (e.g., flash cards, folders, answer tapes) can be beneficial (Cohen \& de Bettencourt, 1988). Self-correcting materials provide the student ongoing feedback on performance and immediate response confirmation, reduce failure experiences, and can increase attention to task (Cohen \& de Bettencourt, 1988).

Self-correcting materials also may be used in conjunction with self-recording or self-graphing to increase motivation. Self-correcting materials are easy to use, and practical. Students are given a seatwork assignment and a correction folder (which contains the answers). Students work as usual, but after each response (or set of responses) they use the correction folder to check their work. Teachers also should remember to give frequent feedback to students on their task engagement (time on-task). Peer tutoring (which will be discussed subsequently) is another extremely effective technique for providing feedback.

\section{Curriculum and Instruction}

Both the curriculum (what's taught) and the instructional methods (how it's taught) can have a major effect on the behavior of students with ADHD. Curricular accommodations can affect stimulation provided by the task, and the extent to which students are engaged in a task. Students are more likely to be actively engaged in learning when they are taught things that they value and find relevant (Glasser, 1992). In the case of students with ADHD, who actively seek much stimulation, this is even more important. Teachers do not always have the authority to develop novel curricular areas; reading and math are required. Nevertheless, they can embed curriculum in personally relevant contexts.

To accommodate students with ADHD, the sequence of the curriculum can be shuffled, its tasks can be broken into small pieces or combined into larger ones, and its organizational structure can be altered (Howell et al., 1993). Instructional variables refer to the interaction between the student and characteristics or the manner in which teachers present the curriculum. Instructional variables can affect students with ADHD. How the teacher presents material and the type of responses students make can directly affect the extent of engagement of students with ADHD. Increasing engagement lessens the likelihood of behavior problems occurring.

\section{Stimulation}

The compliance and attention span of students with ADHD is much longer when they perform activities they perceive as meaningful (e.g., Dunlap, Kern-Dunlap, Clarke, \& Robbins, 1991; Dunlap, White, Vera, Wilson, \& Panacek, 
1996). Therefore, whenever possible curriculum should be couched in a context that interests students. For example, a student's interest in helping with the family grocery shopping led to using newspaper advertisements as a part of reading and vocabulary work. Math work consisted of using the advertised prices to plan a weekly grocery purchase (Dunlap et al., 1996). A problem-solving approach was effective with another student who had problems with math drill and practice. His behavior improved when he was given work that required problem solving, such as reading a menu and computing the cost of a meal (Kern, Childs, Dunlap, Clarke, \& Falk, 1994). Incorporating an outside interest or hobby, photography, proved effective with one severely involved student. Her handwriting assignments were changed from copying pages from a workbook to writing captions for her photographs (Dunlap \& Kern, 1993). One creative teacher managed to "hook" a group of car-crazy adolescent males by incorporating automotive magazines into the curriculum and presenting content areas in this context. For example, a geometry lesson on the area of a cylinder was presented in the context of engine displacement.

In another strategy to make tasks more stimulating, math drill and practice activities are combined with a puzzle. Answers to the questions form a "secret message" that the student can decode. Introducing novelty into the task also can be effective. Zentall (1993) suggested that tasks can be made more stimulating through:

- the addition of color, shape, or texture changes

- varying the format in which tasks are presented (e.g., lecture, seatwork, activity, paper/pencil)

- interspersing high-interest and low-interest tasks

- using tasks which require a motor response as opposed to more passive response

\section{Engagement}

Students with ADHD often have difficulty maintaining cognitive engagement during large-group instruction. Their attention is apt to wander, and they tend to "tune out" or lose interest and, as a result, turn their attention to inappropriate behaviors. An additional concern is that a sizable portion of students with ADHD also have learning disabilities (DuPaul \& Stoner, 1994)

To maximize engagement, teachers must ensure that students can follow lesson content. To accomplish this, teachers must present material at an appropriate level of difficulty/ abstraction, clarify goals and main points to be covered, include step-by-step presentation of new material, provide modeling and demonstrations of new procedures, monitor the students' understanding, adjust instruction as necessary, and provide corrective feedback (Mastropieri \& Scruggs, 1994).
Teachers also must consider the difficulty that some students with ADHD have in attending to more than one task simultaneously. Listening to the instructor and taking notes (especially if their handwriting is laborious or difficult to read) can be a problem for students with ADHD. In this case, the teacher might consider providing the student a copy of the lecture notes, using skeletal outlines to help the student organize notes (Lazarus, 1996), taping lectures so the student can stop the tape to write and start again when ready, or having a peer note taker (the teacher could photocopy the peer's notes or provide carbon paper).

How instruction is delivered can help or hinder a student with ADHD. General guidelines include presenting lessons in an enthusiastic, focused style, avoiding lengthy lectures, and allowing frequent, active responses by the student (Pfiffner \& Barkley, 1998). Holistic or discovery-based approaches probably would not be appropriate for students with ADHD because of their need for structure and difficulty with self-regulation. In contrast, direct instruction techniques, which are fast-paced and highly structured and incorporate frequent student responses, could be an ideal match. Providing students with frequent opportunities to respond, rather than having them sit passively while waiting for an opportunity to respond, is crucial in keeping students with ADHD engaged.

If a student with ADHD has to sit too long, he or she may start calling out, tuning out, or engaging in other inappropriate behavior. High-participation formats can provide more opportunities for response and, hence, increase engagement. One effective technique is the use of response cards (Heward et al., 1996). In this technique, students are given cards to indicate a response. The cards may be in the form of yes/no; $\mathrm{ABCD}$ (for multiple choice), or related to a specific content area (e.g., each card has the name of one famous battle) or erasable slates may be used (best for subjects that require brief responses such as math computation and spelling). Then, during a designated portion of the lesson (or at intervals throughout the lesson), students are questioned and use response cards to answer. This allows all students to participate actively as opposed to the one-at-a-time method, in which all but one student must sit passively.

Another simple but effective technique is to allow students a choice of activities. Several studies have demonstrated the effectiveness of this method for reducing disruptive behaviors and improving work completion in the classroom (Dunlap, Kern-Dunlap, et al., 1991; Dunlap, dePerczel, et al., 1994; Dunlap, White, et al., 1996; Powell \& Nelson, 1997). Students are given a "menu" listing several different tasks (e.g., copy 10 spelling words, do a language arts workbook page, read a selection and answer 5 comprehension questions) and are allowed to pick which task they wish to perform. All tasks are drawn from the gen- 
eral class curriculum and should be at the appropriate level of difficulty. Choice making allows the teacher to utilize existing curriculum with no modifications. It also can be combined with interventions such as token economies (described below).

\section{INTERVENTIONS FOR \\ PROMOTING APPROPRIATE BEHAVIOR}

Interventions for children with ADHD should have a dual thrust. They must focus on both decreasing inappropriate behavior and teaching replacement behaviors that will help the student function better in the classroom (Reid \& Maag, 1998). Reducing or eliminating undesirable behavior is not sufficient. Unless the student is given an appropriate behavior in place of an inappropriate one, problems will recur or a different set of problem behaviors will emerge. No interventions or techniques are specific to students with ADHD. Behavior-modification techniques and other commonly used techniques that work with students with behavior difficulties typically work well with children who have ADHD. Some general guidelines (DuPaul \& Stoner, 1994; Pfiffner \& Barkley, 1998) that should be addressed when using interventions with students who have ADHD include the following.

- Behaviors targeted for intervention should be those that affect the student's (or classmates') academic or social well being negatively. Students with ADHD have many problem behaviors. Those that are most important and most amenable to treatment should be targeted. Behavior to be changed must be well specified prior to intervention. "Impulsiveness," "hyperactivity," and "inattention" are not specific enough. In contrast, "calling out," "out of seat," and "failing to finish assignments" are better specified (see Reid and Maag, 1998 for a detailed discussion).

- Students with ADHD need powerful reinforcers. If naturally occurring reinforcers were sufficient, the child would not have difficulty maintaining appropriate behavior. To determine what reinforcers are best, teachers could provide students with a list of possible reinforcers and allow them to choose which ones they prefer. Or teachers could observe what activities or tangible reinforcers students select when given a choice (Maag, 1999).

- Reinforcement and consequences should be immediate. This is a well established principle that is even more important with students who have ADHD who have trouble delaying gratification. With a few exceptions (see home-school notes, below) consequences (either positive or negative) should closely follow behavior.
- Over time, the power of a given reinforcer might diminish. This phenomenon, termed satiation, is likely with children who have ADHD. To avoid this problem, teachers might change reinforcers periodically or if behavior deteriorates. Instructors should evaluate reinforcers every 2 to 3 weeks (Pfiffner and Barkley, 1998).

- At least initially, students with ADHD should be reinforced for every occurrence of a target behavior (the behavior to be increased) (Douglas \& Parry, 1983; Parry \& Douglas, 1983). Positive reinforcement alone might be ineffective unless it is combined with mild punishers (Pfiffner, Rosen, \& O'Leary, 1985; Rosen, O' Leary, Joyce, Conway\& Pfiffner, 1984). Positive reinforcement should be introduced first, then evaluated for effectiveness. Finally, punishers (e.g., fines, loss of privileges) are introduced if positive reinforcement alone is insufficient to change behavior.

- Behavior problems should be addressed in the setting where they occur. Home-based interventions or interventions taught in one setting (e.g., the resource room) but intended for use in another (e.g., the general education classroom) are not likely to be effective.

- Academics typically should be included as a part of treatment. Many students with ADHD have academic difficulties that are related directly to other problem behaviors. Improved academic performance can result in reduction of other inappropriate behaviors. Problems such as failing to complete assignments, losing work, or sloppy, disorganized work should not be overlooked.

- The student should be involved as much as feasible. Students can provide valuable information on why problem behavior occurs (Reed et al., 1997) and can also help decide what the most appropriate or acceptable intervention might be (Elliot, Witt, Joseph, Galvin, \& Moe, 1986).

Students with ADHD are an extremely heterogeneous group, and the research base of studies conducted in the classroom is small (DuPaul and Eckert, 1997). No one intervention or accommodation will be effective for all students with ADHD or should be implemented with all students who have ADHD. One size does not fit all students with ADHD (DuPaul, Eckert, \& McGooey, 1997). Students' behavior is not random. All behavior occurs within an environmental context and is purposeful. The best results accrue when educators can determine the purpose or function served by a behavior (e.g. to escape from a boring task, seek more stimulation, gain attention) and match the behavior to an appropriate intervention. This process, termed functional assessment, has been shown to be effective and now is mandated 
by IDEA. (For a more detailed discussion and review see DuPaul \& Ervin, 1996; DuPaul, Eckert, \& McGooey, 1997; Reid et al, 1998.)

The following discussion presents inventions that have demonstrated effectiveness with students who have ADHD. First, two punishment techniques will be discussed, followed by positive reinforcement techniques. Finally, selfregulation techniques will be presented. Although the techniques are presented separately, in practice, combining various techniques is often useful. This is especially important in the case of punishers (response cost and time-out), which always should be used in conjunction with positive reinforcement techniques.

\section{Response Cost}

Response cost is the loss of a specific amount of reinforcer contingent upon the performance of an inappropriate behavior. It's analogous to a traffic ticket. If you exceed the speed limit (the inappropriate behavior), you lose a specific amount of a reinforcer (money). Response cost is a powerful technique that is relatively simple to use and is effective with children who have ADHD (e.g., Rapport, Murphy, \&
Bailey, 1982). It is appropriate for situations in which the teacher wishes to reduce or eliminate inappropriate behaviors (e.g. calling out, hitting). Use response cost when positive reinforcement has failed or if a behavior is serious and must be changed immediately. Response cost will not create appropriate behavior; it will only reduce inappropriate behavior. For best results, response cost for inappropriate behavior is combined with positive reinforcement techniques designed to increase appropriate behavior. The steps for using response cost are shown in Table 3.

When using response cost with students who have ADHD, teachers must ensure that powerful reinforcers are available. Teachers also must take care not to misuse fines. Fines should be assessed only when the specified behavior occurs. When fining a student, the teacher should not lecture the student; this actually may serve to reinforce the inappropriate behavior. Instead, the fine is communicated matter-offactly, and the teacher moves on. The effectiveness of response cost should be evaluated closely. If response cost is appropriate, it should result in an immediate and pronounced behavior change. If this does not happen, the teacher should reevaluate the procedure or try another intervention.

\section{TABLE 3 \\ Implementing Response Cost}

\section{Steps}

Conference with the student

Establish the reinforcer

Establish the amount of the fine

Establish the means to communicate the fine

\section{Description}

Tell the student that there is a problem with his or her behavior. Establish the specific behavior that is causing the problem.

Tell the student that you are giving him or her an extra reinforcer (e.g., 15 minutes of computer time, 10 minutes of free time) and when it will be awarded. Then tell the student that any instance of the problem behavior will result in a fine, which means the loss of a portion of the reinforcer.

Tell the student how much the fine will be. For example, each time the student fails to comply with an instruction, he or she will lose 2 minutes of computer time.

The student must know when he or she has been fined. This can be done in many ways. For example, put 10 stars on the chalkboard. Each time the student is fined, erase one star. Or take a piece of paper and cut strips on one end. Tape the paper to the student's desk. Each time he or she is fined, simply tear off one strip. Avoid methods that would cause undue attention to the problem behavior.

The reinforcers and fines in response cost are over and above any normal reinforcers. You don't want students to lose all reinforcement. Then they would have no reason to behave appropriately. 


\section{Time-Out}

Time-out is a punishment procedure in which the student is denied access to the opportunity to receive reinforcement for a fixed time (see Maag, 1999 for a detailed discussion). Table 4 shows several different types of time-out, from least to most severe. Time-out should be reserved for serious behavior (e.g., tantrums, physical aggression, chronic disruptive behavior); exclusion and seclusion time-out are to be used as a last resort if positive reinforcement techniques have failed. Time-out procedures are simple to implement and have been used effectively with students who have ADHD (e.g. Carlson, Pelham, Milich, \& Dixon, 1992; Kubany, Weiss, \& Sloggett, 1971).

Planned ignoring can be extremely effective with students whose behavior is maintained by teacher or peer attention (Umbreit, 1995). The teacher simply ignores inappropriate behaviors and systematically reinforces appropriate behavior. If the student maintains inappropriate behavior, the teacher may have to involve peers. In this case the teacher simply reinforces peers for ignoring the inappropriate behavior.

Another effective use of a time-out procedure is the Good Behavior Clock (Kubany et al., 1971). The student is given a reinforcer (tangible) for each 2-minute interval when he or she behaves appropriately. If the student behaves appropriately for six consecutive intervals, he or she receives a sticker for a Good Behavior Chart. When inappropriate behavior occurs, the clock is stopped for a set interval and the student is cued verbally to behave appropriately. During the interval when the clock is stopped, the student receives no reinforcers. After a short interval, the clock is restarted and reinforcers for appropriate behaviors again are awarded.

If time-out is to be effective, two factors are critical.

1. Most important, time-in (i.e., the normal classroom environment) must be a source of reinforcement for the student. Otherwise, reinforcement is not being withheld from the student. If the classroom is an aversive environment for the student, time-out can serve as a reinforcer, and the student actually may seek time-out. Therefore, time-out is best used in combination with positive reinforcement techniques.

2. Some students with ADHD use inappropriate behavior as a means of avoiding a task or escaping an unpleasant situation. For example, a student might become disruptive to avoid a difficult academic task (e.g., writing a theme or taking a spelling test). In situations

\section{TABLE 4 \\ Levels of Time Out}

Level Description

Planned Ignoring

Time-out Ribbon

Contingent Observation

Exclusion

Seclusion
Planned ignoring involves the systematic removal of social reinforcers contingent upon the occurrence of maladaptive behavior. This may involve the teacher, other students, or both. The teacher refrains from any physical, verbal, or visual interaction with the student until a designated period is completed.

A ribbon (or other device) serves as a cue for teachers and other students to deliver high levels of social reinforcement. When the child misbehaved, the ribbon was removed and reinforcement withheld for a designated period. Upon the next occurrence of appropriate behavior, the ribbon was replaced and the child again received high levels of social reinforcement from teachers and peers.

In this procedure, a student is removed from, or not allowed to participate in, a group activity for a fixed time, contingent upon his or her undesired behavior. The student remains in a position to observe the group but may neither participate nor receive any form of reinforcement.

Here the student is completely removed from the time in setting and placed in a location devoid of reinforcement (e.g., in a chair in the hallway).

The student is placed in a specially designed isolation room or cubicle for a short time. Seclusion time-out is the most restrictive and the most controversial level of this intervention. 
such as this, time-out will not be effective because it allows the student to escape the task and thereby actually serves to reinforce the inappropriate behavior.

Teachers must realize that time-out procedures have the potential for abuse. Removing a student from the classroom might serve to reinforce the teacher. Teachers must carefully monitor their use of time-out and its effectiveness. Time-out procedures should result in immediate reductions in inappropriate behavior. If time-out is effective in reducing behavior, it should be used less frequently over time because inappropriate behavior should decrease. If time-out at the exclusion or seclusion level is used, teachers should document that use (i.e., for each time-out, maintain a record of date, type of time-out, duration, and the behavior).

\section{Token Economy}

Token economies provide students with a token (e.g., a poker chip or a point) for performing appropriate behavior. These tokens can be redeemed later for reinforcers (e.g. free time, soda, lunch with the teacher). Token economies are an excellent means of increasing appropriate behavior for students with ADHD who need reinforcement over and above that which normally occurs in the classroom. This strategy has been used effectively in numerous studies (DuPaul \& Stoner, 1994) and can result in dramatic improvement
(Robinson, Newby, \& Ganzell, 1981). A token economy can be used alone or in conjunction with other interventions (such as response cost or peer tutoring). Token economies can be used on an individual or a large-group basis. They also can be integrated into the academic curriculum. For example, teachers can set up a banking system in which students have individual bank accounts (for tokens). Table 5 shows the steps in setting up a token economy.

When using token economies with students with ADHD, teachers must set the initial behavior standards (i.e., the type and amount of behavior a student must exhibit) at a level that ensures that students will receive enough tokens to purchase reinforcers. Standards always can be raised later. Setting standards too high initially, however, likely will result in failure because the student will not be reinforced. Directly teaching and modeling appropriate behaviors may be useful to ensure that students understand exactly what is expected of them. Providing students with individual cues/reminders or posting behaviors and corresponding token awards prominently also might be helpful. The behavior to increase must be in the child's repertoire already. If "raising your hand for attention" is a target behavior, the student must already perform this behavior. If not, the behavior should be taught directly.

The frequency with which tokens are awarded is important. Because students with ADHD have difficulty deferring

\section{TABLE 5 \\ Implementing a Token Economy}

Steps Description

Select a target behavior(s)

Make and post rules

Selecting tokens

Establish back-up reinforcers

Establish "prices"

Field-test the system
Make behaviors specific, and include the criteria for acceptable performance (e.g., stayed in seat during math time). Begin with a small number of behaviors - no more than three to five. Too many behaviors will be confusing for a student and difficult for a teacher to manage. Always include one or two behaviors that are easy for students to perform.

Be sure students understand the rules, including: (1) when tokens will be dispensed; (2) how many tokens are to be awarded for a behavior; and (3) times when students can play with tokens (this established them as reinforcers).

Make sure the actual tokens are safe, durable, and easily handled and dispensed.

Exchange tokens for reinforcers. To establish reinforcers, use reinforcement menus, ask students for suggestions, or observe students' choice of activities.

State how many tokens must be earned to get a given reinforcer.

Before actually starting, field-test the system by tallying the points that a student would earn. This will help to set initial prices appropriately and ensure that the student receives tokens. 
gratification, awarding tokens and allowing them to purchase reinforcers at frequent intervals might be useful. After the system is well established, intervals can be lengthened. Response cost can easily be combined with token economies through the use of "fines" for inappropriate behaviors. The behaviors that result in fines should be well specified, included in the rules, and explicitly taught to students. The teacher also must take care not to overuse fines. Students should receive three to five tokens for every token they are fined (Maag, 1999).

\section{Peer Tutoring}

Peer tutoring combines active responding under circumstances utilizing individualized highly structured academic content presented at a student's pace (DuPaul \& Stoner, 1994). It is simple to implement, appropriate for the general education and special education environments alike, and effective in increasing students' academic performance. It affords students with ADHD an ideal instructional environment that provides ongoing one-to-one peer attention, offers frequent prompting to attend to task, eliminates "wait time," and gives students recurrent, immediate performance feedback.

Two types of peer tutoring have been used with students who have ADHD.

1. Classwide peer tutoring (CWPT), in which an entire class or large groups are divided into competing teams with points awarded for daily performance

\section{Standard peer tutoring.}

Both methods have demonstrated great promise for students with ADHD. Peer-tutoring can increase academic responding, attention to task, and academic learning while decreasing noncompliance and inappropriate motor activity such as fidgeting or not remaining in seat (DuPaul \& Hennington, 1993; DuPaul, Ervin, Hook, \& McGooey, 1998; Locke \& Fuchs, 1995). Peer tutoring also may benefit the teacher by decreasing the need to monitor behavior during peer-tutoring time, and providing time that could be spent in one-to-one instruction or small-group instruction with other students.

Research has shown that standard peer-tutoring methods are effective without specialized alterations. For CWPT, the use of daily points may provide useful performance feedback; the points also might be used along with a token economy. The use of performance charting or graphing also may improve performance or motivation (Locke \& Fuchs, 1995).

\section{School-Home Notes}

School-home notes comprise a simple, effective technique for elementary-age children who have ADHD (Kelley \& McCain, 1995; McCain \& Kelly, 1993). A sample schoolhome note is shown in Figure 1. This technique utilizes a contingency contract. The teacher and the student establish well-specified performance levels for behaviors (e.g., no more than two times out of seat during the morning). Concurrently, the parents and child establish rewards for fulfilling the contract.

Each day a contract is placed on the student's desk. This helps to cue the student to the expected behavior. The teacher monitors behavior throughout the period for which the contract is in force (e.g., the morning) and then records how well the student performed. The school-home note is returned to the parents each day. If the student attains his or her daily goal, the parents supply an agreed upon reinforcer. The process is repeated daily. Performance levels may be raised after behavior improves.

Although all positive contracts can be effective, a response cost component should be used for best results, (Kelley \& McCain, 1995). For example, in the example school-home note, each time the student acts aggressively, a star is crossed off the note (hands and feet to self) and 3 minutes of bonus computer time is lost. School-home notes require little teacher time, and they also provide ongoing information to parents on their children's behavior.

School-home notes also can yield positive feedback to parents. Too often, the only communication that parents receive from the school is negative (e.g. complaints about inappropriate behavior). For school-home notes to be effective, the parents must be taught the procedures and provide the agreed-upon reward when their child earns it and only when the child earns it. Teachers must carefully evaluate parents' ability to follow procedures correctly and consistently. Parents of children with ADHD sometimes exhibit ADHD symptoms themselves, so their ability to follow procedures correctly and consistently might be a factor in deciding whether this technique would be appropriate. In addition, teachers must consider the possibility that parents may react negatively if contract goals are not met.

\section{Self-Regulation Techniques}

Many children with ADHD have the skills to perform the desired behaviors but are not able to perform the behaviors consistently or maintain performance over time because of a lack of self-regulation skills (Harris \& Schmidt, 1997). For these students, self-regulation techniques such as self-monitoring or self-management can be useful. These techniques are simple and effective with students who have attention problems (e.g., Reid, 1996; Shapiro \& Cole, 1994). Further, they have the advantage of requiring little or no teacher time after they are actually implemented and thus may be preferable to other techniques that are more demanding of teacher time. 


\section{HOW DID I DO THIS MORNING?}

I stayed in my seat

\section{Hands and Feet to Self?}
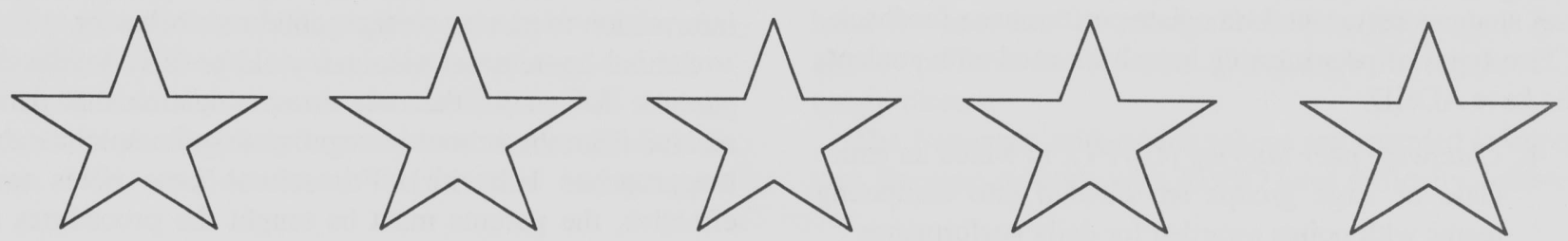

I need at least 2 OKs to get my reward. If I get 1 super and one OK, I get a bonus.

I get 3 minutes of computer time for each star I have left.

\section{Self-monitoring}

Self-monitoring is a technique in which students selfassess whether they are or are not performing a specified target behavior and then self-record the results. Steps for implementing self-monitoring are shown in Table 6 (for a detailed overview of self-monitoring procedures, see Reid, 1993). The self-monitoring technique used most frequently with students who have ADHD is self-monitoring of attention. It typically is used during academic seatwork. Several studies have shown that self-monitoring of attention can improve time on-task and academic performance and decrease inappropriate behavior (Christie, Hiss, \& Lozanoff, 1984); De Haas-Warner, 1992; Mathes, \& Bender, 1997; Barkley,
Copeland, \& Sivage, 1980). In this technique, a tape containing tones at random intervals (usually ranging from 10 to 90 seconds) is played. Students are instructed to listen for the tone. When they hear the tone, they are to ask themselves, "Was I paying attention?" and mark either a yes or no on a tally sheet.

This technique can be used with minimal changes for students who have ADHD. Teachers may encounter two possible problems.

1. Students must self-assess and self-record at frequent intervals; if the length of intervals becomes too great, student performance may deteriorate (Barkley et al., 1980). 


\section{TABLE 6}

\section{Implementing Self-Monitoring}

Steps Description

Select a Target Variable

Collect Baseline Data

Obtain Willing Cooperation

Instruct in Self-Monitoring Procedures

Give Independent Practice
Four considerations are involved in selecting a target behavior: (1) the behavior must be well specified so the child can accurately self-assess; (2) the behavior should be one that the child can easily observe; impulsive behavior or behaviors the child is not aware of might be poor target behaviors; (3) the behavior should be appropriate for the setting and task; (4) the behavior should be a good personal match.

After the target behavior(s) has been selected, baseline data should be gathered and recorded. Baseline data allow for assessment of effectiveness after selfmonitoring begins.

Because the students, rather than the teacher, actually "run" the intervention, they must agree to trying the procedure. Schedule a conference with the student to address the problem area(s) frankly. Point out the benefits the student would derive by improving his or her behavior-frame self-monitoring as "something that has helped a lot of other students like you with the same kind of problem."

Four steps are involved in ensuring that students learn the self-monitoring procedures. First, the teacher explains the procedure. Second, the teacher models the steps while verbalizing. Third, the teacher models the steps while the student verbalizes them. Finally, the student models and verbalizes the steps.

During the first few times students engage in independent self-monitoring, it is important to observe them to be sure that they follow the procedures consistently and properly. Reminding the student to perform the procedure for the first few sessions might be necessary.
2. Students may not perform the procedures consistently or correctly.

Sometimes students fail to self-assess when they are cued by tones. If this happens, teachers can tell students that they will receive a reinforcer if the number of tallies they make matches the number of tones (plus or minus one). To reinforce children for the number of "yes" tallies is generally not a good idea. This can lead to misrepresenting behavior. Alternatively, the teacher may physically cue the student to self-assess and self-record (Christie et al., 1984). Another problem arises when students cannot accurately assess whether they performed the target behavior. Using videotapes of the student might be useful in teaching the student to accurately self-assess (Christie et al., 1984).
Self-monitoring also can be used in other situations and can be combined with other techniques. For example, Fraser, Belzner, and Conte (1992) used an egg timer to indicate the 5-minute period during which transition tasks occur (e.g., coming inside, removing outer clothing, putting on inside shoes, and sitting on carpet with legs crossed). Before each transition, the egg timer was set for 5 minutes. For each of the transition tasks completed within the allotted 5 minutes, the student self-recorded by putting a stamp next to a picture of each activity in a book. The stamps also served as tokens for back-up reinforcers. If the student met agreedupon standards for 3 consecutive days, he also received bonus computer time.

When these procedures were implemented, the student immediately began to perform transition activities $100 \%$ of 
time with no prompting. The teacher was able to expand use of the procedure to other periods and activities.

\section{Self-management}

Self-management techniques combine teacher evaluation and student self-evaluation. Self-management methods have been shown to be effective in reducing disruptive behavior, are appropriate for both special education and general education settings, and are well accepted by teachers and students alike (Hinshaw \& Melnick, 1992; Hoff, \& DuPaul, 1998). Steps for implementing self-management (adapted from Hoff \& DuPaul, 1998; and Shapiro and Cole, 1994) are shown in Table 7 . Figure 2 provides an example of a recording sheet. When implementing self-management techniques, the student has to understand the relationship between behavior and ratings. Hoff and DuPaul (1998) used a scale in which:

\footnotetext{
$5=$ Excellent - followed all rules for the entire interval

4 = Very Good-one minor infraction, but followed rules for the rest of interval

3 = Average - followed rules for the most part with no serious offenses

2 = Below Average-broke one or more rules to the extent that behavior was unacceptable

1 = Poor-broke one or more rules for almost entire interval, behavior generally unacceptable

$0=$ Totally Unacceptable: broke one or more rules during the entire interval (p. 294)
}

\section{TABLE 7}

\section{Implementing Self-Management}

Steps Description

Establish Rules and Back-up Reinforcers

Rate the Student

Match with feedback

Match without feedback

Implement Interval Extension

Fade Matching

Self-Management
Discuss classroom rules with the student. Inform the student that his or her behavior will be rated by the teacher and that the student will receive reinforcement based on performance. Discuss the rating system and demonstrate how to use the recording sheet. Establish when rating will occur and the length of the interval over which the student will be rated. Inform the student that they can earn points based on ratings. They can redeem these points for back-up reinforcers decided upon jointly.

The teacher cues the student that he or she will be rated. At the end of the rating interval, the teacher meets briefly with the student, tells the rating, discusses why the rating was awarded, and awards points.

In this stage the student receives reinforcement for accurately self-evaluating behavior. At the end of each interval, the teacher and student independently rate behavior. The ratings then are compared and discussed. The student receives a reinforcer if his or her rating matches the teacher's rating closely (e.g., within 1). Students could receive bonus points for matching the teacher rating exactly.

Points are awarded without discussion unless the student's rating differs from the teacher's rating by 2 or more points.

The intervals during which the student and teacher rates behavior are lengthened systematically (e.g. from 5 to 15 minutes).

Matching is faded gradually. Students keep the points they would earn based on their ratings. If behavior deteriorates, "surprise matches" occur, in which the student must once again match the teacher's rating.

The student rates his or her behavior and self-awards points. No teacher action is required. 


\section{HOW DID I DO TODAY?}

Did I follow directions?

Did I complete my work?
Did I listen quietly?

Did I respect others?

5

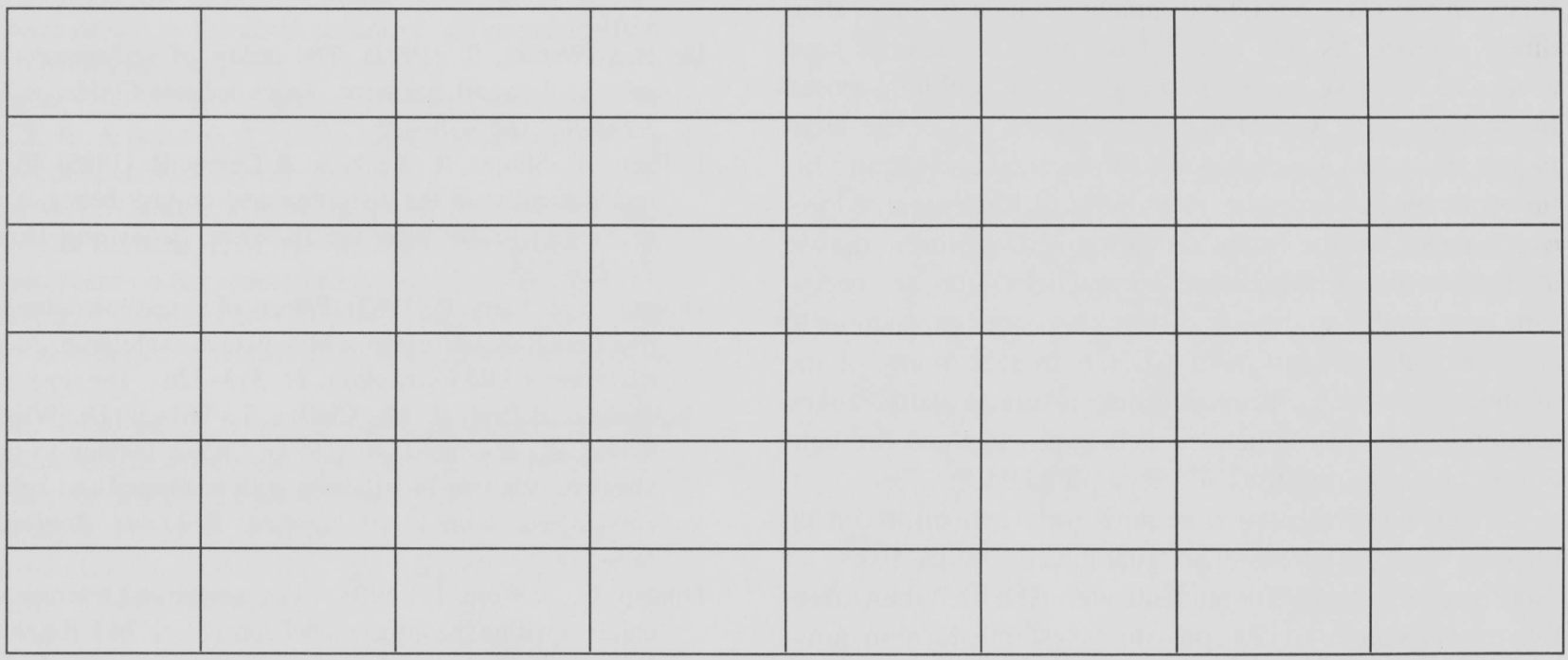

FIGURE 2

Sample Self-Management Rating Form

If the student's rating is within 1 point of the teacher's rating, the student is allowed to keep the points (i.e., the rating they assigned themselves). If the student and the teacher ratings match exactly, bonus points may be awarded. If ratings differ by more than 2 , no points are awarded. Note that points are not awarded for high ratings; they are awarded for accurately matching the teacher's rating.

One potential problem with self-management is that initially intervals are quite short (i.e., from 5 to 15 minutes). This may pose a burden, especially in the case of the general education teacher.

One excellent solution is the use of paraeducators. Paraeducators can be trained to run interventions effectively, and some intervention programs actually are constructed around the paraeducator (e.g., Kotkin, 1998). The paraeducator can begin the program, award points, and match ratings. After the student's behavior has improved and intervals have been lengthened substantially, the teacher can take over the program. The payoff for self-management is worth the effort. This technique can instill self-regulated behavior that will maintain.

\section{CONCLUSIONS}

How we perceive ADHD is a critical factor in intervention. Imagine for a moment that you are trying on a new pair of shoes. When you try to slip them on, you find that the shoes are much too small for your foot. They pinch painfully when you stand, and you can barely walk. How can this problem be solved? Luckily, the solution here is simple environmental accommodation: Try a slightly larger pair.

For children with ADHD, the classroom environment can be like the too-tight shoe. Behavioral expectations of the classroom may be painful. Unfortunately, in too many cases, the response is to require the student to conform to the classroom environment. As a result, problem behaviors actually are exacerbated. In the case of the too-tight shoes, this would be analogous to making the shoe fit by cutting off the toes-clearly an unreasonable solution. Expecting children with ADHD to change their make-up independently is equally unreasonable.

We cannot change the child's make-up. Medication does not cure ADHD. Children do not outgrow ADHD. The best 
evidence to date suggests that for most, ADHD behavior will be a lifelong problem. Instead, the focus must be on how to alter the environment to better fit the child's needs. From this perspective, behavior problems are seen as the result of a mismatch between the classroom environment and the student's needs.

This perspective empowers educators. It allows them to focus on the classroom environment-which is under their direct control. As this article has shown, educators have access to effective methods to address the problems posed by students with ADHD in the classroom. All of the techniques discussed are common and practical and require little or no special expertise or training to implement. Moreover, none of the methods discussed requires drastic alterations to existing classroom practices. It is not necessary or desirable to grossly distort classroom procedures to accommodate students with ADHD. In fact, many of the methods used (e.g., peer tutoring, response cards, token economies) are recommended as best practice and can benefit all children, not just children with ADHD.

Effective treatment will require time and effort on an ongoing basis. There are no guaranteed "quick fixes" or "sure-fire" treatments for students with ADHD. When effective methods are used in a consistent, systemic fashion, however, the chances for a successful outcome are good.

\section{REFERENCES}

Abramowitz, A. J., \& O’Leary, S. (1991). Behavioral interventions for the classroom: Implications for students with ADHD. School Psychology Review, 20, 220-234.

Abramowitz, A. J., Reid, M. J., \& O'Toole, K. (1994). The role of task timing in the treatment of ADHD. Paper presented at Association for the Advancement of Behavior Therapy, San Diego, CA.

Acker, M., \& O'Leary, S. (1987). Effects of reprimands and praise on appropriate behavior in the classroom. Journal of Abnormal Child Psychology, 15, 549-557.

American Psychiatric Association. (1994). Diagnostic and statistical manual of mental disorder (4th ed.). Washington, DC: APA.

Barkley, R. A. (1998). Attention deficit hyperactivity disorder: A handbook for diagnosis and treatment ( $2 d$ ed.). New York: Guilford Press.

Barkley, R. A., Copeland, A. P., \& Sivage, C. (1980). A self-control classroom for hyperactive children. Journal of Autism and Developmental Disorders, 10, 75-89.

Bender, W. N. \& Mathes, M. Y. (1995). Students with ADHD in the inclusive classroom: A hierarchical approach to strategy selection. Intervention in School \& Clinic, 30, 226-234.

Carlson, C. L., Pelham, W. E., Milich, R., \& Dixon, J. (1992). Single and combined effects of methylphenidate and behavior therapy on the classroom performance of children with attention-deficit hyperactivity disorder. Journal of Abnormal Child Psychology, 20, 213-232.
Christie, D. J., Hiss, M., \& Lozanoff, B. (1984). Modification of inattentive classroom behavior: Hyperactive children's use of self-recording with teacher guidance. Behavior Modification, 8, 391-406

Cohen, S., \& de Bettencourt, L. (1988). Teaching children to be independent learners: A step by step strategy. In E. L. Meyen, G. L. Vergason, \& R. J. Whelan (Eds.), Effective instructional strategies for exceptional children (pp. 319-334). Denver: Love.

De Haas-Warner, S. (1992). The utility of self-monitoring for preschool on-task behavior. Topics in Early Childhood Special Education, 12, 478-495.

DePaepe, P., Shores, R., Beck, S., \& Denny, R. (1996). Effects of task difficulty on the disruptive and on-task behavior of students with severe behavior disorders. Behavioral Disorders, 21, 216-225.

Douglas, V. \& Parry, P. (1983). Effects of reward on delayed reaction time task performance of hyperactive children. Journal of Abnormal Child Psychology, 11, 313-326.

Dunlap, G., dePerczel, M., Clarke, S., Wilson, D., Wright, S., White, R., \& Gomez, A. (1994). Choice making to promote adaptive behavior for students with emotional and behavioral challenges. Journal of Applied Behavior Analysis, 27, 505-518.

Dunlap, G., \& Kern, L. (1993). Assessment and intervention for children within the instructional curriculum. In J. Reichle \& D. Wacker (Eds.), Communication alternatives to challenging behavior: Integrating functional assessment and intervention strategies (pp. 177-203). Baltimore: Paul H. Brookes.

Dunlap, G., Kern-Dunlap, L., Clarke, S., \& Robbins, F. R. (1991). Functional assessment, curricular revision, and severe behavior problems. Journal of Applied Behavior Analysis, 24, 387-397.

Dunlap, G., White, R., Vera, A., Wilson, D., \& Panacek, L. (1996). The effects of multi-component, assessment-based curricular modifications on the classroom behavior of children with emotional and behavioral disorders. Journal of Behavioral Education, 6, 481-500.

DuPaul, G. J. \& Eckert, T. (1997). The effects of school-based interventions for attention deficit hyperactivity disorder: A meta-analysis. School Psychology Review, 26, 5-27.

DuPaul, G. J., Eckert, T. L., \& McGooey, K. E. (1997). Interventions for students with attention-deficit/hyperactivity disorder: One size does not fit all. School Psychology Review, 26, 369-381.

DuPaul, G. J. \& Ervin, R. A. (1996). Functional assessment of behaviors related to attention-deficit/hyperactivity disorder: Linking assessment to intervention design. Behavior Therapy, 27, 601-622.

DuPaul, G. J., Ervin, R. A., Hook, C. L., \& McGooey, K. E. (1998). Peer tutoring for children with attention deficit hyperactivity disorder: Effects on classroom behavior and academic performance. Journal of Applied Behavior Analysis, 31, 579-572.

DuPaul, G. J., \& Hennington, P. A. (1993). Peer tutoring effects on the classroom performance of children with attention deficit hyperactivity disorder. School Psychology Review, 22, 134-143. 
DuPaul, G. J., \& Stoner, G. (1994). ADHD in the schools: Assessment and intervention strategies. New York: Guilford.

Elliot, S., Witt, Joseph, C., Galvin, G., \& Moe, G. (1986). Children's involvement in intervention selection: Acceptability of interventions for misbehaving peers, Professional Psychology Research \& Practice, 17, 235-241.

Fraser, C., Belzner, R., \& Conte, R. (1992). Attention deficit hyperactivity and self-control: A single case study of the use of a timing device in the development of self-monitoring. School Psychology International, 13, 339-345.

Glasser, W. (1992). The quality school. New York: HarperCollins.

Harris, K. R., \& Schmidt, T. (1997). Learning self-regulation in the classroom. ADHD Report, 5(2), 1-6.

Heward, W. L., Gardner, R., Cavanaugh, R., Courson, F. H., Grossi, T. A., \& Barbetta, P. M. (1996). Everyone participates in this class. Focus on Exceptional Children, 28(2), 4-10.

Hinshaw, S. \& Melnick, S. (1992). Self-mangement therapies and attention-deficit hyperactivity disorder. Behavior Modification, 16, 253-273.

Hoff, K., \& DuPaul, G. J. (1998). Reducing disruptive behavior in general education classrooms: The use of self-management strategies. School Psychology Review, 27, 390-303.

Howell, K. W., Fox, S. L., \& Morehead, M. K. (1993). Curriculumbased evaluation: Teaching and decision making ( $2 \mathrm{~d}$ ed.). Pacific Grove: CA: Brooks/Cole.

Kelley, M. L., \& McCain, A.P. (1995). Promoting academic performance in inattentive children. Behavior Modification, 19, 357-375.

Kern, L., Childs, K., Dunlap, G., Clarke, S., \& Falk, G. (1994). Using assessment-based curricular intervention to improve the classroom behavior of a student with emotional and behavioral challenges. Journal of Applied Behavior Analysis, 27, 7-19.

Kotkin, R. (1998). The Irvine Paraprofessional Program: Promising practice for serving students with ADHD. Journal of Learning Disabilities, 31, 556-564.

Kubany, E. S., Weiss, L. E., \& Sloggett, B. B. (1971). The good behavior clock: A reinforcement/time out procedure for reducing disruptive classroom behavior. Journal of Behavior Therapy \& Experimental Psychiatry, 2, 173-179.

Lazarus, B. D. (1996). Flexible skeletons: Guided notes for adolescents. Teaching Exceptional Children, 28(3), 36-40.

Lewis, T. J., \& Sugai, G. (1996). Functional assessment of problem behavior: A pilot investigation of the comparative and interactive effects of teacher and peer social attention on students in general education settings. School Psychology Quarterly,11, $1-19$.

Locke, W. R., \& Fuchs, L. S. (1995). Effects of peer-mediated reading instruction on the on-task behavior and social interaction of children with behavioral disorders. Journal of Emotional \& Behavioral Disorders, 3, 92-99.

Maag, J. W. (1999). Behavior management. San Diego: Singular Publishing Group.

Mastropieri, M.A., \& Scruggs, T.E. (1994). Effective instruction for special education (2d ed.). Austin, TX: Pro-Ed.

Mathes, M. Y., \& Bender, W. N. (1997). The effects of self-monitoring on children with attention-deficit/hyperactivity disorder who are receiving pharmacological interventions. Remedial \& Special Education, 18, 121-128.

McCain, A. P. \& Kelley, M. L. (1993). Managing the classroom behavior of an ADHD preschooler: The efficacy of a schoolhome note intervention. Child and Family Behavior Therapy, $15,33-44$.

Northrup, J., Broussard, C., Jones, K., George, T., Vollmer, T. R., \& Herring, M. (1995). The differential effects of teacher and peer attention on the disruptive classroom behavior of three children with a diagnosis of attention deficit hyperactivity disorder. Journal of Applied Behavior Analysis, 28, 227-228.

Paine, S. C., Radicchi, J., Rosellini, L. C., Deutchman, L., Darch, C. (1983). Structure your classroom for success. Champaign, IL: Research Press.

Parry, P., \& Douglas, V. (1983). Effects of reinforcement on concept identification in hyperactive children. Journal of Abnormal Child Psychology, 11, 327-340.

Pfiffner, L. J. \& Barkley, R. A. (1998). Treatment of ADHD in school settings. In R. A. Barkley (Ed.), Attention deficit hyperactivity disorder: A handbook for diagnosis and treatment $(2 d$ ed) (pp. 458-490). New York: Guilford.

Pfiffner, L., \& O'Leary, S. (1987). The efficacy of all-positive management as a function of the prior use of negative consequences. Journal of Applied Behavior Analysis, 20, 265-271.

Pfiffner, L., Rosen, L., \& O'Leary, S. (1985). The efficacy of an all- positive approach to classroom management. Journal of Applied Behavior Analysis, 18, 257-261.

Powell, S., \& Nelson, B. (1997). Effects of choosing academic assignments on a student with attention deficit hyperactivity disorder. Journal of Applied-Behavior-Analysis, 30(1): 181-183.

Rapport, M. D., Murphy, H. A., \& Bailey, J. S. (1982). Ritalin vs. response cost in the control of hyperactive children: A withinsubject comparison. Journal of Applied Behavior Analysis, 15, 205-216.

Reed, H., Thomas, E., Sprague, J., \& Horner, R. H. (1997). The student-guided functional assessment interview: An analysis of teacher and student agreement. Journal of Behavioral Education, 7, 33-49.

Reid, R. (1993). Implementing self-monitoring interventions in the classroom: Lessons from research. Monograph in Behavior Disorders: Severe Behavior Disorders in Youth, 16, 43-54.

Reid, R. (1996). Self-monitoring for students with learning disabilities: The present, the prospects, the pitfalls. Journal of Learning Disabilities, 29, 317-331.

Reid, R., \& Katsiyannis, A. (1995). Attention deficit-hyperactivity disorder and Section 504. Remedial \& Special Education, 16, 44-52.

Reid, R. \& Maag, J. (1998). Functional assessment: A method for developing classroom-based accommodations for children with ADHD. Reading and Writing Quarterly, 14, 9-42.

Reid, R., Maag, J. W.,Vasa, S. F., \& Wright, G. (1994) Who are the children with ADHD: A school-based survey. Journal of Special Education, 28, 117-137.

Reid, R., Reason, R., Maag, J., Xu, C., \& Prosser, B. (1998). ADHD: A perspective on perspectives. Educational \& Child Psychology, 15, 56-67. 
Robinson, P. W., Newby, T. J., \& Ganzell, S. L. (1981). A token system for a class of underachieving hyperactive children. Journal of Applied Behavior Analysis, 14, 307-315.

Rosen, L. A., O’ Leary, S., Joyce, S., Conway, G., \& Pfiffner, L. (1984). The importance of prudent negative consequences for maintaining the appropriate behavior of hyperactive students. Journal of Abnormal Child Psychology, 12, 581-604.

Shapiro, E. S. \& Cole, C. L. (1994). Behavior change in the classroom. New York: Guilford.

Umbreit, J., (1995). Functional assessment and intervention in a regular classroom setting for the disruptive behavior of a student with attention deficit hyperactivity disorder. Behavioral Disorders, 20, 267-278.
Whalen, C. K., Henker, B., Collins, B. E., Finck, D., \& Dotemoto, S. (1979). A social ecology of hyperactive boys: Medication effects in structured classroom environments. Journal of Applied Behavior Analysis, 12, 65-81.

Zentall, S. (1993). Research on the educational implications of attention deficit hyperactivity disorder. Exceptional Children, $60,143-153$.

\section{PERMISSIONS AND COPYRIGHT}

All rights are reserved. No part of this publication may be reproduced, photocopied, faxed, stored in a retrieval system, or transmitted in any form or by any means, electronic, mechanical, recording or otherwise, without the prior written permission of the publisher.
Back issues are available for sale. Reproduction requires permission and payment of fees. It is illegal and a violation of federal copyright law to reproduce this publication without permission. Direct all inquiries to the permissions editor. 